\title{
Efficient Statistical Planning of Fire Experiments
}

OLE KR. BULIEN (1), PER JOSTEIN HOVDE (2) and TORGRIM LOG (1)

(1) National College of Safety Engineering. Skaaregaten 103, N-5500 Naugesund, Norway, Tel.: +47527212 00, Fax : +4752715906.

(2) University of Trondheim. Norwegian Institute of Technology, Dep. of Building and Construction Engineering, Alfred Getz road 3, N-7034 Tronheim.

\begin{abstract}
Statistics is a natural tool for any experimenter to minimize the number of tests without loosing the wanted information, and to ensure that the results are statistically valid. A proper test design also makes it easier to interpret data and to produce a mathematical model of the response variable being studied. This document contains a quick introduction to the fields of statistical planning and analysis of data, and shows that this is a way to save time for a research scientist dealing with fire experiments. The theory is illustrated with a few concrete, simple examples from Cone Calorimeter testing.
\end{abstract}

Keywords : Fire testing, statistics, Cone Calorimeter

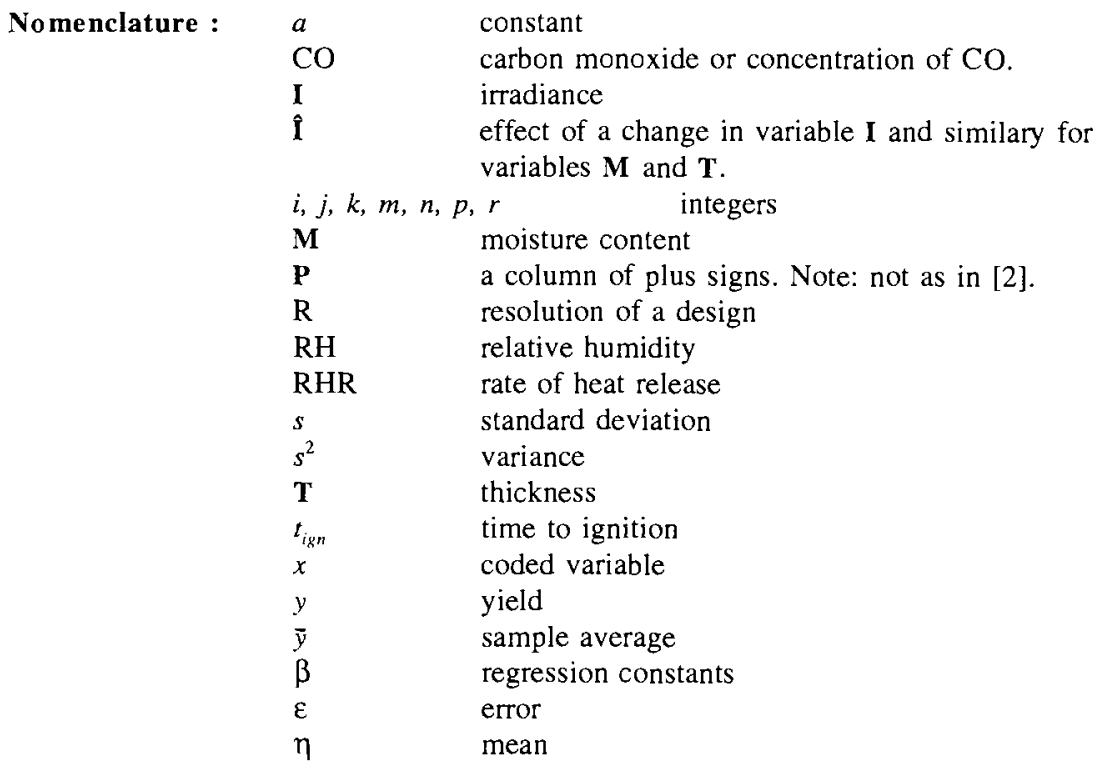




\section{INTRODUCTION}

For an experimenter in the field of fire science, experiments and analysis of data occupy much of the time available for research. For example, performing Cone Calorimeter [1] tests, the time consumed for each test run is associated with :

* Preparation of the specimen (2-5 minutes)

* Calibration prior to the test run including data setup (2-15 minutes)

* $\quad$ Running the test (2-60 minutes).

It is obvious that reducing the number of tests gives considerable time and cost savings. The time saved can alternatively be used to perform more replicates to increase the reliability of results, or to analyse the data more thoroughly.

Several methods to design a test programme are described by Box et al. [2]. The present paper focuses on factorial designs at two levels and Yates' method.

\section{FULL FACTORIAL DESIGNS AT TWO LEVELS}

The main advantages with factorial designs are :

* A few runs indicate the main features and further experimenting.

* Further examination of special combinations is simple.

* A large number of variables can be taken into account.

* Interpretation can be done by common sense and simple arithmetics.

* The way to a mathematical model is short.

When carrying out an investigation of the response variable rate of heat release (RHR) (yield) from burning particle board in the Cone Calorimeter, the variables that may have an effect on RHR must be defined. Only three factors are considered important in our simplified example, namely irradiance to the surface of the board, or the heat flux (I), moisture content (M) and thickness of the specimen (T). Each of these variables are given a low and a high level, chosen with care and sense. To investigate this problem, $2^{3}=8$ test runs with different conditions are needed, see Figure 1. Using at least three replicates at each scenario, gives a total of at least 24 test runs. It is possible to investigate this $2^{3}$-problem by varying one variable at the time and obtain the same information. If we increase the design to $k$ variables $(k>3)$ the traditional methods get difficult to handle and we loose synergetic effects. The experimenter will then gain from putting the tests into a system.

There are several advantages by setting up the test programme after Yates' Algorithm shown in Table 1. The minus signs illustrate the lower level of the variables and the plus signs the upper level. A $2^{k}$ factorial design is in standard order when, as in Table $\mathbf{1}$, the first column of the design matrix consists of succesive minus and plus signs, the second column of succesive pairs of minus and plus signs, the third column of four minus signs followed by four plus signs, and so fourth. In general, the $k$ th column consists of $2^{k-1}$ minus signs followed by $2^{k-1}$ plus signs. 
TABLE 1: The full $2^{3}$ factorial design.

\begin{tabular}{||c|c|c|c|}
\hline \hline Test nr. & I & M & T \\
\hline \hline $\mathbf{1}$ & - & - & - \\
\hline $\mathbf{2}$ & + & - & - \\
\hline $\mathbf{3}$ & - & + & - \\
\hline $\mathbf{4}$ & + & + & - \\
\hline $\mathbf{5}$ & - & - & + \\
\hline $\mathbf{6}$ & + & - & + \\
\hline $\mathbf{7}$ & - & + & + \\
\hline $\mathbf{8}$ & + & + & + \\
\hline
\end{tabular}

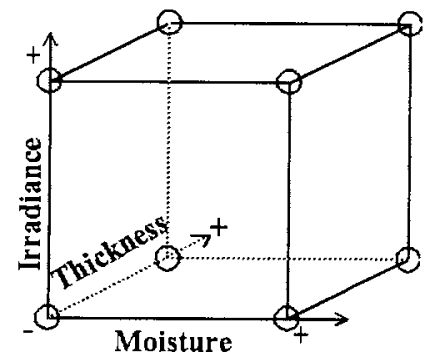

FIGURE 1 : The geometry of the $2^{3}$ design.

The basis of this way to set up a design is :

-The "overall" error $\varepsilon=y-\eta$ is usually approximated by a linear sum of independent and identically distributed component errors with mean zero and variance $\sigma^{2}$.

$$
\varepsilon=a_{1} \varepsilon_{1}+a_{2} \varepsilon_{2}+\cdots+a_{\mathrm{n}} \varepsilon_{\mathrm{n}}
$$

-The central limit theorem states that in the real world the "overall" error $\varepsilon$ will tend to normality, regardless of the parent distributions, under the condition that no single source of error dominates the rest.

- To be able to treat the data as random samples from a normal distribution, the tests should be run in a random succession. Randomization helps to avoid trends caused by time dependent changes in the test apparatus.

These qualifications are used to interpret the data in a proper way, as explained below.

Let the response yields be $y_{\mathrm{i}}$ in Table 2, where index $i$ indicates the test number. The yield may be the sample average from all the tests made under the same conditions (replicates).

TABLE 2 : Result diagram for a $2^{3}$ design.

\begin{tabular}{||c|c|c|c|c|c|c|c|c||}
\hline \hline Test nr. & I & M & T & IM & IT & MT & IMT & Yield $\left(\mathbf{y}_{i}\right)$ \\
\hline \hline $\mathbf{1}$ & - & - & - & + & + & + & - & $\mathrm{y}_{1}$ \\
\hline $\mathbf{2}$ & + & - & - & - & - & + & + & $\mathrm{y}_{2}$ \\
\hline $\mathbf{3}$ & - & + & - & - & + & - & + & $\mathrm{y}_{3}$ \\
\hline $\mathbf{4}$ & + & + & - & + & - & - & - & $\mathrm{y}_{4}$ \\
\hline $\mathbf{5}$ & - & - & + & + & - & - & + & $\mathrm{y}_{5}$ \\
\hline $\mathbf{6}$ & + & - & + & - & + & - & - & $\mathrm{y}_{6}$ \\
\hline $\mathbf{7}$ & - & + & + & - & - & + & - & $\mathrm{y}_{7}$ \\
\hline $\mathbf{8}$ & + & + & + & + & + & + & + & $\mathrm{y}_{8}$ \\
\hline
\end{tabular}


The effect on the response (or yield $y$ ) of changing one of the variables from the lower level $(-)$ to the higher level (+) can now be calculated directly from :

$$
\text { Effect of variable } j=\frac{2}{2^{k}} \cdot\left(\sum y_{+}-\sum y_{-}\right)
$$

where $\Sigma y_{+}$is the sum of yields of the investigated response parameter under which the variable $j$ has been at the higher level, and equally for the lower level $\Sigma \boldsymbol{y}$. . In particular, $\hat{\mathbf{i}}$ is the effect on the response of the variable I when you raise it from the lower to the higher level, and similar for the other variables.

For the variable I the following is correct :

$$
\Sigma_{\mathbf{y}_{+}}=\mathbf{y}_{2}+\mathbf{y}_{4}+\mathbf{y}_{6}+\mathbf{y}_{8} \quad \text { and } \quad \boldsymbol{\Sigma}_{\mathbf{y}_{-}}=\mathbf{y}_{1}+\mathbf{y}_{3}+\mathbf{y}_{5}+\mathbf{y}_{7}
$$

and for variable $\mathbf{M}$ the same calculation becomes :

$$
\Sigma_{y_{+}}=y_{3}+y_{4}+y_{7}+y_{8} \quad \text { and } \quad \Sigma_{y_{2}}=y_{1}+y_{2}+y_{5}+y_{6}
$$

In a full factorial design it is possible to calculate synergy effects in the same simple way. Interaction beetween $\mathbf{I}$ and $\mathbf{M}$, for example, takes the name IM. Each interaction has its own column of signs, as shown in Table $\mathbf{2}$. The signs for the interaction IM are obtained by multiplying the signs in colomn I with the signs in column M. This makes it possible to calculate the effect of the interactions by applying Eq. (1) to the IM column.

It is neccesary to conclude whether the effects are significant or not. The effects are compared to an estimate of the standard deviation of the effect. There are several ways to obtain this estimate, but if there are two or more $(n)$ replicates, standard deviation of each combination of variables $\boldsymbol{s}_{v i}$ are calculated using Eq. (2a), where $i=1, \ldots, 2^{k}$.

$$
s_{v i}=\sqrt{\frac{\sum_{r=1}^{n}\left(y_{i}-\bar{y}\right)^{2}}{n-1}}
$$

Each standard deviation of a combination of variables has $r$-1 degrees of freedom. It is assumed that all yields has the same standard deviation. The estimate of the standard deviation of the effect, $s$, is then calculated from :

$$
s=\sqrt{\frac{\sum_{i=1}^{2^{k}} s_{v}^{2}}{2^{k}}}
$$

Alternatively, produce a table of ANalysis Of VAriance (ANOVA), see Table 3, as a preliminary to further statistical analysis. An effect has always one degree of freedom. 
TABLE 3 : Analysis of variance for a $2^{k}$ design with $r$ replicates.

$r$ replicates : $\mathrm{i}=1, \ldots, \mathrm{r}$

Test numbers : $v=1, \ldots, 2^{k}$

\begin{tabular}{|c|c|c|c|c|}
\hline \multicolumn{5}{|c|}{ ANOVA } \\
\hline Sources & Sum of squares (SS) & $\begin{array}{c}\text { Degrees of } \\
\text { freedom (DF) }\end{array}$ & $\begin{array}{l}\text { Mean square } \\
(M S)=\text { SS } / D F\end{array}$ & $\begin{array}{c}\text { Ratio of mean } \\
\text { squares } \\
\text { MS/MS }_{\text {ERR }}\end{array}$ \\
\hline $\mathbf{I}$ & $\mathrm{SS}_{\mathrm{I}}=\mathrm{r} 2^{\mathrm{k}-2}(\hat{\mathbf{I}})^{2}$ & 1 & $\mathrm{MS}_{\mathrm{I}}$ & $\mathrm{MS}_{\mathrm{I}} / \mathrm{MS}_{\mathrm{ERR}}$ \\
\hline $\mathbf{M}$ & $\mathrm{SS}_{\mathrm{M}}=\mathrm{r} 2^{\mathrm{k}-2}(\widehat{\mathbf{M}})^{2}$ & 1 & $\mathrm{MS}_{\mathrm{M}}$ & $\mathrm{MS}_{\mathrm{M}} / \mathrm{MS}_{\mathrm{ERR}}$ \\
\hline $\mathbf{T}$ & $\mathrm{SS}_{\mathrm{T}}=\mathrm{r} 2^{\mathrm{k}-2}(\widehat{\mathbf{T}})^{2}$ & 1 & $\mathrm{MS}_{\mathrm{T}}$ & $\mathrm{MS}_{\mathrm{T}} / \mathrm{MS}_{\mathrm{ERR}}$ \\
\hline · & $\cdot$ & . & $\cdot$ & $\cdot$ \\
\hline$\cdot$ & . & . & $\begin{array}{l}\cdot \\
.\end{array}$ & . \\
\hline IMT & $\mathrm{SS}_{\mathrm{IMT}}=\mathrm{r} 2^{\mathrm{k}-2}(\widehat{\mathbf{M T}})^{2}$ & 1 & $\mathrm{MS}_{\mathrm{IMT}}$ & $\mathrm{MS}_{\mathrm{IMT}} / \mathrm{MS}_{\mathrm{ERR}}$ \\
\hline Error & \multicolumn{2}{|c|}{ Found by subtraction } & $\mathrm{MS}_{\mathrm{ERR}}$ & \\
\hline Total & $\mathrm{SS}_{\mathrm{TOT}}=\sum_{\mathrm{i}} \sum_{\mathrm{v}}\left(\mathrm{y}_{\mathrm{iv}}-\overline{\mathrm{y}}_{\mathrm{all}}\right)^{2}$ & $2^{k} r-1$ & $\mathrm{MS}_{\mathrm{TOT}}$ & \\
\hline
\end{tabular}

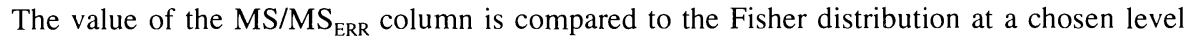
of significance (say $5 \%$ ), with $v_{1}$ and $v_{2}$ degrees of freedom (DF), where $v_{1}$ is the degrees of freedom of the variable and $v_{2}$ is the DF of the error. This comparision tests the null hypothesis : The variable has no effect on the response. If the value in the $M S / M S_{E R R}$ column is greater than the tabulated value from the Fisher distribution, the null hypothesis is discredited by the experiment and the variable has a significant effect on the response at the $5 \%$ level of significance.

\section{Example of a $\underline{2}^{2}$ Full Factorial Design}

One of the objectives of the work of Bulien [3], was to conclude whether water resistant particle board specimens behaved differently in a fire compared to the regular particle board. Particle board specimens of thickness $22 \mathrm{~mm}$ from Agnes, Norway, were used for the tests. The design is shown in Table $\mathbf{4}$ and $\mathbf{5}$. Three replicates were tested in each combination of variables. The calculated effects of the variables are given in Table $\mathbf{6}$.

TABLE 4: Design levels and variables for Agnes particle board.

\begin{tabular}{||l|c|c||}
\hline Level & - & + \\
\hline \hline Heat flux & $25 \mathrm{~kW} / \mathrm{m}^{2}$ & $50 \mathrm{~kW} / \mathrm{m}^{2}$ \\
\hline Water resistance & No & Yes \\
\hline
\end{tabular}


TABLE 5: Test design. The response is shown as sample averages.

\begin{tabular}{|c|c|c|c|c|c|c|}
\hline \multirow{3}{*}{$\begin{array}{l}\text { Test } \\
\text { number }\end{array}$} & \multirow{3}{*}{$\begin{array}{l}\text { Heat } \\
\text { flux }\end{array}$} & \multirow{3}{*}{$\begin{array}{l}\text { Water } \\
\text { resistance }\end{array}$} & \multirow[t]{3}{*}{ Interaction } & \multicolumn{3}{|c|}{ Response } \\
\hline & & & & \multirow[t]{2}{*}{$t_{\mathrm{ign}}[\mathrm{s}]$} & \multicolumn{2}{|c|}{ RHR/time-plot } \\
\hline & & & & & $\begin{array}{c}\text { 1.peak } \\
{[\mathrm{kW} / \mathrm{m} 2]}\end{array}$ & $\begin{array}{c}\text { 2.peak } \\
{[\mathrm{kW} / \mathrm{m} 2]}\end{array}$ \\
\hline$\# 1-\# 3$ & - & - & + & 129 & 173 & 115 \\
\hline$\# 4-\# 6$ & + & - & - & 23 & 198 & 106 \\
\hline \#7-\#9 & - & + & - & 141 & 219 & 103 \\
\hline$\# 10-\# 12$ & + & + & + & 33 & 258 & 112 \\
\hline
\end{tabular}

TABLE 6: Effect of the variables on the response. Significant effects are underlined.

\begin{tabular}{|l||l|l|c|}
\hline \multirow{2}{*}{$\begin{array}{l}\text { Changing the } \\
\text { variable from the } \\
\text { lower level to the } \\
\text { higher }\end{array}$} & \multirow{2}{*}{$\mathrm{t}_{\mathrm{ign}}[\mathrm{s}]$} & \multicolumn{2}{|c||}{ RHR/time-plot } \\
\cline { 2 - 4 } & & $1 . p e a k[\mathrm{~kW} / \mathrm{m} 2]$ & 2.peak $[\mathrm{kW} / \mathrm{m} 2]$ \\
\hline Heatflux & -107 & $\underline{32}$ & 0 \\
\hline Water resistance & 11 & $\underline{53}$ & -3 \\
\hline Interaction & -1 & 7 & 9 \\
\hline
\end{tabular}

The effect of imbuement of the particle board is of special interest. The design conclude that there is a significant difference between the regular and the water resistant particle board with respect to $t_{i g h}$ and rate of heat release at an early stage of a fire. There are no synergetic effect.

\section{Blocking}

A block is a part of a design that is expected to be more homogeneous than the whole design. Blocking may reduce the variance if the assumption above is valid. If not, the reduction of degrees of freedom, which is caused by the blocking, may increase the variance. A special ANOVA [2] is used to investigate the variation within the block and between the blocks. The latter is expected to be greater than the former. The effect of the blocking is of no interest, and is eliminated through the design, while the effect of the specimen treatment is visualized.

Blocking is confounded (mixed together) with interactions of higher order, and these interaction effects are lost from the analysis. It is clear that the blocks has to be chosen carefully. 
The following rule of thumb should be used while making a factorial design :

Block what you can, randomize what you can not (block).

The tool of blocking is necessary in many cases. For example when it is impossible to run the whole design in one single day. This is normal for Cone Calorimeter tests if the design consists of more than $8-12$ runs.

\section{FRACTIONAL FACTORIAL DESIGNS AT TWO LEVELS}

The initial design may well tell the experimenter that one or more of the variables have no effect at all, or that the levels of one of the variables are chosen unfavourable. In this case time can be saved by running only a fraction of a full factorial design initially. If necessary, it is possible to run the tests to complete the design later. A fractional design is written

$$
2_{R}^{k-m}
$$

where $k \cdot m \geq 2$, and $R$ beeing the resolution of the design. The resolution is typically III, IV or $\mathrm{V}$, but not less than III. The highest possible resolution is preferred.

In general, a design of resolution $\mathrm{R}$ is one where no $p$-factor effect is confounded (mixed together) with any other effect containing less than $\mathrm{R}_{-p}$ factors.

We pursue this matter with an example were $m=1$. The case of $m=1$ gives a half-fraction of a full factorial design.

In Table 1, we had a full $2^{3}$ design with $2^{3}=8$ different combinations of levels. The halffraction has only four combinations of levels. The Yates' algorithm will then be repeated only over four lines. To make this $2^{3-1}$ design, one (or in general, $m$ ) of the columns of signs are generated by multiplying together other columns of signs. In other words, the effect of $\boldsymbol{m}$ variables is confounded with interactions. In order to achive the highest possible resolution, as many columns as possible should be multiplied together to generate the $m$ variables.

To make a $2^{3-i}$ design of the previous example, the signs of one of the columns, e.g. $\mathbf{T}$ are the products of the signs of $\mathbf{I}$ and $\mathbf{M}$, written $\mathbf{T}=\mathbf{I} \mathbf{M}$. The design given in Table $\mathbf{7}$, and shown geometrically in Figure 2, has resolution III. 
TABLE 7: A $2^{3-1}$ design with resolution III.

\begin{tabular}{||c|c|c|c|c|c||}
\hline $\begin{array}{c}\text { Test } \\
\text { number }\end{array}$ & I & M & $\begin{array}{c}\text { T = } \\
\text { IM }\end{array}$ & $\begin{array}{c}\text { IT }= \\
\text { M }\end{array}$ & $\begin{array}{c}\text { MT } \\
=\text { I }\end{array}$ \\
\hline $\mathbf{1}$ & - & - & + & - & - \\
\hline 2 & + & - & - & - & + \\
\hline 3 & - & + & - & + & - \\
\hline 4 & + & + & + & + & + \\
\hline
\end{tabular}

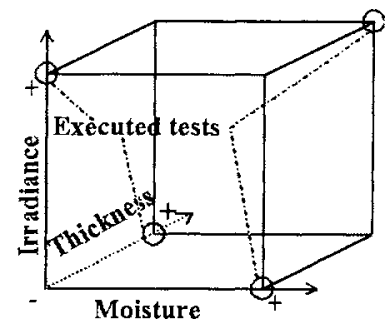

FIGURE 2 : The geometry of the $2^{3-1}$ design.

Multiplying any column by a column of identical signs gives a column of plus signs, which is designated by the letter $\mathbf{P}$.

$$
\mathbf{P}=\mathbf{I} \cdot \mathbf{I}=\mathbf{M} \cdot \mathbf{M}=\mathbf{T} \cdot \mathbf{T}=\mathbf{I} \mathbf{M T} \cdot \mathbf{I} \mathbf{M T}
$$

As shown in Table 7, $\mathbf{T}$ was generated by $\mathbf{T}=\mathbf{I M}$. If this expression is multiplied with $\mathbf{T}$ on both sides, we obtain :

$$
\mathrm{T}=\mathrm{IM} \quad \Rightarrow \quad \mathrm{TT}=\mathrm{IMT} \quad \Rightarrow \quad \mathrm{P}=\mathrm{IMT}
$$

The last expression is called the defining relation of the design. If $m>1$, the defining relation contains more than one equality. The resolution equals the number of letters in the shortest combination in the defining relation. When the defining relation is known, it is easy to find which interactions the main effects are confounded with. For example, the main effect $I$ is confounded with MT. This is obtained by multiplying both sides of the defining relation with I.

$$
\mathbf{P}=\text { IMT } \quad \Rightarrow \quad \text { IP }=\text { IIMT } \Rightarrow \text { I }=\text { MT }
$$

The effect in a fractional factorial design calculated by Eq. (1) is not the effect of the main variable only, but the sum of effects from the main variable and the confounded interactions. Two options now exist :

to assume that the effect of all, or some, of the confounding interactions can be neglected.

* to perform a 'fold-over' and run the tests necessesary to separate the main effects from the confounding effects. In a 'fold-over' the plus and minus signs in one run are exactly reversed in the second. Note that if $m>1$, the 'fold-over' will not complete a factorial design, and special methods has to be applied [2]. 
It is worth noting that :

1. The experimenter should randomize within each fraction.

2. If it is eventually decided to run both fractions, these fractions will be randomized orthogonal blocks of the complete design.

3. No information will be lost except information concerning the interaction which is actually confounded with the block contrast (in our example : the three factor interaction is confounded with the block effect).

4. The design run as two randomized fractions can give greater precision than the hole design run in random order since the block difference is eliminated.

\section{$\underline{\text { Resolution }}$}

Resolution is here defined as the act of separating the design into constituent parts. Suppose that the experimenter has a number of candidate variables, but believe that only R-1 of them have a detectable effect on the response. Then, if he employs a design of resolution $R$, he will have a complete factorial design in the effective variables if his conjecture is justified. This idea is illustrated in Figure 3, which projects a $2^{2}$ pattern in every subspace of two dimensions.

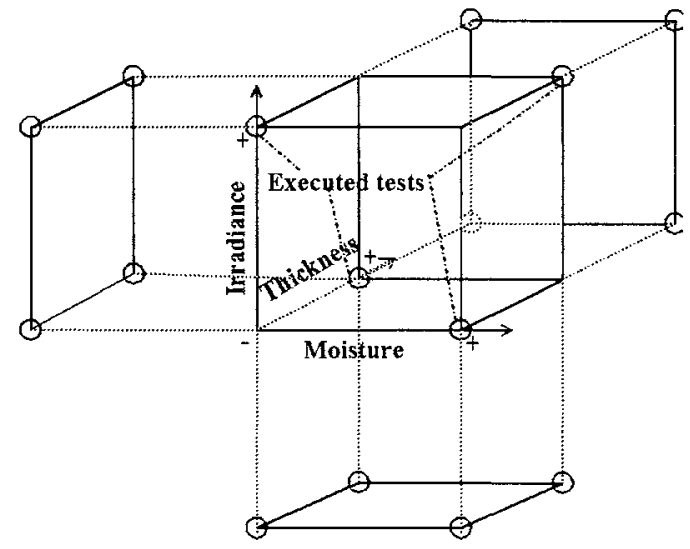

FIGURE 3 : A $2^{3-1}$ design showing the remaining design if one of the three variables has no effect.

\section{Example of a $2^{3-1}$ Fractional Factorial Design with Resolution III}

In the previous work [3], floor particle board from Orkla, Norway, was tested in a Cone Calorimeter [1]. The design is given in Tables 8 and 9. The objective of the work was to investigate the rate of heat release (RHR) and the production of carbon monoxide as a function of heat flux, plate thickness and moisture content. 
TABLE 8 : Design levels for Orkla particle board.

\begin{tabular}{|c|c|c|}
\cline { 2 - 3 } \multicolumn{1}{c|}{} & - & + \\
\hline $\mathbf{I}$ & $25 \mathrm{~kW} / \mathrm{m}^{2}$ & $50 \mathrm{~kW} / \mathrm{m}^{2}$ \\
\hline $\mathbf{T}$ & $12 \mathrm{~mm}$ & $20 \mathrm{~mm}$ \\
\hline $\mathbf{M}$ & $<1 \%$ & $\approx 10 \%$ \\
\hline
\end{tabular}

TABLE 9 : Test design for Orkla particle board.

\begin{tabular}{|l|c|c|c|}
\hline $\begin{array}{l}\text { Test } \\
\text { number }\end{array}$ & I & T & $\begin{array}{c}\text { M= } \\
\text { IT }\end{array}$ \\
\hline$\# 1-\# 4$ & - & - & + \\
\hline$\# 5-\# 8$ & + & - & - \\
\hline$\# 9-\# 12$ & - & + & - \\
\hline$\# 13-\# 15$ & + & + & + \\
\hline
\end{tabular}

TABLE 10: Response in sample averages \pm one standard deviation. Standard deviations exeeding $10 \%$ of the response are underlined.

\begin{tabular}{|c|c|c|c|c|c|c|c|c|c|c|}
\hline \multirow{3}{*}{$\begin{array}{c}\text { Test } \\
\text { number }\end{array}$} & \multirow{3}{*}{ I } & \multirow{3}{*}{$\mathbf{T}$} & \multirow{3}{*}{$\mathbf{M}$} & \multicolumn{7}{|c|}{ Reading on the response } \\
\hline & & & & \multirow{2}{*}{$\begin{array}{l}t_{\text {ign }} \\
{[s]}\end{array}$} & \multicolumn{3}{|c|}{ RHR/time-plot } & \multicolumn{3}{|c|}{$\mathrm{CO} /$ time-plot } \\
\hline & & & & & $\begin{array}{c}\text { 1.peak } \\
{\left[\mathrm{kw} / \mathrm{m}^{2}\right]} \\
+ \text { Time } \\
{[\text { Min }]}\end{array}$ & $\begin{array}{c}\text { Intermediate } \\
\text { minimum } \\
{\left[\mathrm{kw} / \mathrm{m}^{2}\right]} \\
+ \text { Time }[\mathrm{Min}]\end{array}$ & $\begin{array}{c}\text { 2.peak } \\
{\left[\mathrm{kw} / \mathrm{m}^{2}\right]} \\
+ \text { Time } \\
{[\text { Min] }]}\end{array}$ & $\begin{array}{c}\text { 1.peak } \\
\text { [ppm] } \\
+ \text { Time } \\
\text { [Min] }\end{array}$ & $\begin{array}{c}\text { 2.peak } \\
\text { [ppm] } \\
+ \text { Time } \\
\text { [Min] }\end{array}$ & $\begin{array}{l}\text { 3.peak } \\
{[\text { ppm }]} \\
+ \text { Time } \\
{[\text { Min] }}\end{array}$ \\
\hline$\# 1-\# 4$ & - & - & + & $\begin{array}{l}169 \\
\pm 6\end{array}$ & $\begin{array}{c}104 \\
\pm 8 \\
3,8 \\
\pm 0,2\end{array}$ & $\begin{array}{c}64 \\
\pm 7 \\
9,0 \\
\pm 0,4\end{array}$ & $\begin{array}{l}157 \\
\pm 11 \\
13,3 \\
\pm 0,5\end{array}$ & $\begin{array}{c}28 \\
\pm 3 \\
4,0 \\
\pm 0,1\end{array}$ & $\begin{array}{c}41 \\
\pm 6 \\
13,3 \\
\pm 0,5\end{array}$ & $\begin{array}{l}149 \\
\pm 15 \\
16,1 \\
\pm 0,3\end{array}$ \\
\hline$\# 5-\# 8$ & + & $=$ & - & $\begin{array}{l}34 \\
\pm 2\end{array}$ & $\begin{array}{c}199 \\
\pm 8 \\
1,4 \\
\pm 0,1\end{array}$ & $\begin{array}{c}122 \\
\pm 9 \\
4,7 \\
\pm 0,2\end{array}$ & $\begin{array}{c}187 \\
\pm 14 \\
7,3 \\
\pm 0,3\end{array}$ & $\begin{array}{c}56 \\
\pm 4 \\
1,7 \\
\pm 0,1\end{array}$ & $\begin{array}{c}62 \\
\pm 5 \\
7,2 \\
\pm 0,3\end{array}$ & $\begin{array}{l}\sim 75^{1} \\
\sim 15\end{array}$ \\
\hline$\# 9-\# 12$ & - & + & - & $\begin{array}{l}131 \\
\pm 3\end{array}$ & $\begin{array}{c}131 \\
\pm 2 \\
3,3 \\
\pm 0,2\end{array}$ & $\begin{array}{c}63 \\
\pm 3 \\
11,8 \\
\pm 0,4\end{array}$ & $\begin{array}{l}128 \\
\pm 12 \\
19,2 \\
\pm 0,3\end{array}$ & $\begin{array}{c}24 \\
\pm 1 \\
3,4 \\
\pm 0,3\end{array}$ & $\begin{array}{c}26 \\
\pm 10 \\
19,1 \\
\pm 0,3\end{array}$ & $\begin{array}{c}113 \\
\pm 7 \\
22,6 \\
\pm 0,7\end{array}$ \\
\hline$\# 13-\# 15$ & + & + & + & $\begin{array}{l}50 \\
\pm 1\end{array}$ & $\begin{array}{c}149 \\
\pm 2 \\
1,9 \\
\pm 0,1\end{array}$ & $\begin{array}{c}60 \\
\pm 1 \\
10,2 \\
\pm 0,1\end{array}$ & $\begin{array}{c}101 \\
\pm 2 \\
18,3 \\
\pm 0,9\end{array}$ & $\begin{array}{c}32 \\
\pm 3 \\
2,4 \\
\pm 0,3 \\
\end{array}$ & $\begin{array}{c}6 \\
\pm 2 \\
17,8 \\
\pm 0,9\end{array}$ & $\begin{array}{c}85 \\
\pm 3 \\
28,7 \\
\pm 0,8\end{array}$ \\
\hline $\begin{array}{r}\text { Estimi } \\
(\text { Eq }\end{array}$ & mat & ed & & 4 & $\begin{array}{c}6 \\
0,2\end{array}$ & $\begin{array}{c}6 \\
0,3\end{array}$ & $\begin{array}{c}11 \\
0,5\end{array}$ & $\begin{array}{c}3 \\
0,2\end{array}$ & $\begin{array}{c}6 \\
0,5\end{array}$ & $\begin{array}{l}11 \\
0,7\end{array}$ \\
\hline
\end{tabular}

1 These tests were unfortunately not run for a time period long enough to read maximum $\mathrm{CO}-$ consentration. At this time the fire was smouldering. 
TABLE 11: Effect of changes in the levels of input variables on the response variables. These effects have been compared with the standard deviations (Table 10) to separate effects from noise. The interaction effects are assumed to be negligible. Small effects compared to an estimate (Eq. (2b)) are underlined, while more significant effects are double underlined.

\begin{tabular}{|c|c|c|c|c|c|c|c|}
\hline \multirow[b]{3}{*}{$\begin{array}{l}\text { Input } \\
\text { variable }\end{array}$} & \multicolumn{7}{|c|}{ Effect on response } \\
\hline & \multirow{2}{*}{$\begin{array}{l}\mathbf{t}_{\mathrm{ign}} \\
{[\mathbf{s}]}\end{array}$} & \multicolumn{3}{|c|}{ RHR } & \multicolumn{3}{|c|}{$\mathrm{CO}_{\max }$} \\
\hline & & $\begin{array}{c}\text { 1.peak } \\
{\left[\mathrm{kw} / \mathrm{m}^{2}\right]} \\
+ \text { Time } \\
{[\text { Min] }}\end{array}$ & $\begin{array}{c}\text { Intermediate } \\
\text { minimum } \\
{\left[\mathrm{kw} / \mathrm{m}^{2}\right]} \\
+ \text { Time }[\mathrm{Min}]\end{array}$ & $\begin{array}{c}\text { 2.peak } \\
{\left[\mathrm{kw} / \mathrm{m}^{2}\right]} \\
+ \text { Time } \\
{[\text { Min] }}\end{array}$ & $\begin{array}{c}\text { 1.peak } \\
\text { [ppm] } \\
+ \text { Time } \\
\text { [Min] }\end{array}$ & $\begin{array}{c}\text { 2.peak } \\
{[\mathrm{ppm}]} \\
+ \text { Time } \\
\text { [Min] }\end{array}$ & $\begin{array}{c}\text { 3.peak } \\
\text { [ppm] } \\
+ \text { Time } \\
{[\text { Min] }}\end{array}$ \\
\hline \multirow[t]{2}{*}{ Heat flux } & $\underline{\underline{-108}}$ & $\underline{\underline{56,5}}$ & 25.5 & 1,5 & $\underline{18}$ & 0,5 & -51 \\
\hline & & $\underline{\underline{-1,9}}$ & $\underline{\underline{-2.95}}$ & $-3,45$ & $\underline{-1,65}$ & $-3,7$ & $\underline{2,5}$ \\
\hline \multirow[t]{2}{*}{ Thickness } & -11 & -11.5 & -31.5 & -57.5 & $\underline{\underline{-14}}$ & $-\underline{\underline{35,5}}$ & -13 \\
\hline & & 0 & $\underline{\underline{4,15}}$ & $\underline{\underline{8.45}}$ & 0,05 & $\underline{\underline{8,2}}$ & $\underline{\underline{10,1}}$ \\
\hline \multirow{2}{*}{$\begin{array}{l}\text { Moisture } \\
\text { content }\end{array}$} & $\underline{\underline{27}}$ & $\underline{\underline{-38.5}}$ & $\underline{\underline{-30.5}}$ & $-28,5$ & -10 & $-20,5$ & $\underline{23}$ \\
\hline & & $\underline{0,5}$ & $\underline{1.35}$ & $\underline{2.55}$ & $\underline{0.65}$ & $\underline{2.4}$ & $\underline{3,6}$ \\
\hline
\end{tabular}

The units of the effects are the same as that of the response parameters. Results that need interpretation and discussions, can now be obtained from Table 11. All input variables have significant effects. A more reliable analysis of the interaction effects is obtained by performing the tests belonging to the unmarked corners of Figure 2, which will give a full factorial design. Note that if only the time to l.peak RHR was under investigation, the thickness has no effect, and we would have a complete factorial design in the remaining variables.

\section{RESPONSE SURFACE METHOLOGY}

The goal of many test programmes is to express the response, or yield, in terms of a mathematical model. The yield can be regarded as a surface in one, two or multiple dimensions. The algorithm to make and check a linear model for the yield $y$ as a function of two variables $x_{1}$ and $x_{2}$ is simple. The linear model may be expressed as:

$$
\mathbf{y}=\beta_{0}+\beta_{1} \mathbf{x}_{1}+\beta_{2} \mathbf{x}_{2}+\varepsilon
$$

assuming that the effect of each variable is additive and linear, and that no interactions exsist. $\beta_{0}$ is the average of all measured yields in any level combination in the design, $\beta_{1}$ and $\beta_{2}$ are constants which express the effects of the two factors, and $\varepsilon$ is the error (or the noise). 
The variables previously given by plus and minus signs are in this example coded as $x_{1}$ and $x_{2}$ such that when the actual level values are inserted, the coded variables equals either -1 or +1 . In the centre of the design, the values of $x$ are zero. Note that coding can be done at more than three levels [2]. The constant $\beta_{1}$ is easily calculated, since is can be shown that $\beta_{1}$ equals half of the effect of variable 1 in a full factorial design, and equally for $\beta_{2}$. The interaction effect between two variables can be handled by adding a term of the type $+\beta_{12} \cdot x_{1} \cdot x_{2}$ to the model.

Further on it is usual to perform a curvature check, an estimation of error and to make a contour diagram of the response. The next step then may be to generate a second test design in the direction of steepest ascent of the response surface.

Weather Eq. (4) describes the response surface properly or not, may be checked using a special ANOVA. This may indicate that a nonlinear model would fit better. For each model this must be checked using the above algorithm until the required accuracy is obtained.

\section{CONCLUSIONS}

This paper is not enough to educate fire scientists to be better experimenters, will rather open their eyes to a powerful tool in their work. Box, Hunter \& Hunter [2] provides a good start. Further information is available [4] if the experimenter deals with several response variables at the same time, such as with the Cone Calorimeter, and wants to investigate the connections between for example the RHR and the production of $\mathrm{CO}_{2}$. Statistics is often regarded as a difficult profession. On the other hand, the more knowlegde of statistical planning, the more the experimenter is able to use it.

The work presented in this paper and in the previous work [3] clearly demonstrates that efficient statistical planning of fire experiments is a helpful tool to reduce time consumption seeking conclusive, statistically valid results

\section{REFERENCES:}

1. ISO 5660 : Fire tests - reaction to fire.

2. Box, G.E.P., Hunter, W.G. and Hunter, J.S., Statistics for experimenters, John Wiley \& Sons, Inc. 1978.

3. Bulien, O.K., Fire testing of particle board by a Cone Calorimeter, National College of Safety Engineering, Norway. 1993.

4. Johnson, R.A. and Wichern, D.W., Applied multivariate statistical analysis, Third edition, Prentice-Hall International, 1992. 